\title{
Relevant Factors in Assessing Vulnerability of Urban Systems in Latin-American Cities
}

\author{
Paula Kapstein López ${ }^{1, *}$, Massimo Palme ${ }^{1}$, Gino Pérez Lancellotti ${ }^{1}$, Miguel Ángel Gálvez \\ Huerta $^{2}$
}

${ }^{1}$ School of Architecture, Catholic University of the North, Antofagasta, Chile.

${ }^{2}$ School of Architecture, Universidad Técnica Federico Santa María, Valparaíso, Chile

E-Mails: pkapstein@ucn.cl (PKL), mpalme@ucn.cl (MP), gperez@ucn.cl (GPL), miguel.galvez@usm.cl (MAGH)

* Author to whom correspondence should be addressed; Tel.: +56-552-355391; Fax: +56-552-355431

Received: 3 September 2014 / Accepted: 29 October 2014 / Published: 1 November 2014

\begin{abstract}
Urban vulnerability of a city is difficult to quantify, basically because of the difference among variables that contribute to its definition. Some of these variables have their origin in environmental processes and could be estimated by using efficiency indicators, others are more difficult to evaluate because of their dependence on social phenomena. Furthermore, additional difficulties arise from the fact that such different variables have to be somewhat weighed when it comes to assessing the global vulnerability. In this work some ideas related to an interdisciplinary and holistic approach are presented and discussed, developing a methodology to assess metabolism and resilience of cities under social, environmental and urban planning points of view. Preliminary results of study cases in northern Chile are also presented to justify the use of the proposed methodology as predictive instrument of interventions in middle size cities.
\end{abstract}

Keywords: urban resilience, vulnerability, energy efficiency, urban systems, Latin-America

\section{Introduction}

Urban vulnerability is one of the most discussed items of the sustainable development. In the recently concluded $7^{\text {th }}$ World Urban Forum, one of the aspects to be included in Post 2015 Un-Habitat Agenda was the social justice and resilience of cities [1]. In this work some conclusions of the meeting 
"Urban resiliency: Ideas for an integral methodology of recovery of vulnerable areas in Latin American cities" are presented. Meeting took place at the WUF in Medellín where different experts dialogued on urban resilience, metabolism and vulnerability. One of the objectives of this work was to determinate the importance of the absence of urban planning in the origin of urban vulnerability. In this way we defined the issues and parameters that will configure a methodology to assess vulnerability in three areas: environmental, social and town planning factors.

\section{Three pillars of vulnerability}

First screening produced as important factors the following: urban metabolism, energy use efficiency, smart grids, urban grow definition, social inclusion through participative projects and accessibility improvement. This work contributes to broaden the parameter selection and to suggest a possible way of "vulnerability" and "resilience" indicators construction, taking into account the difficulty to compare different variables, as discussed by many authors [2, 3]. As stated during the WUF meeting, vulnerability is considered here as a concept with a minimum of three dimensions: environmental, social and planning factors are equally important in assessing it. The three aforementioned areas permit to define urban vulnerability as a critic situation generated by social, environmental and town planning problems. This situation presents a high complexity, which can be observed in a superposition of related facts: social inequity, deterioration of the environment and the natural landscape and an urban space fragmentation [4].

Figure 1. Calle Atacama (Antofagasta, Chile). The social segregation and the urban fragmentation can be observed as a whole reality. Fuente: P. Kapstein, 2009

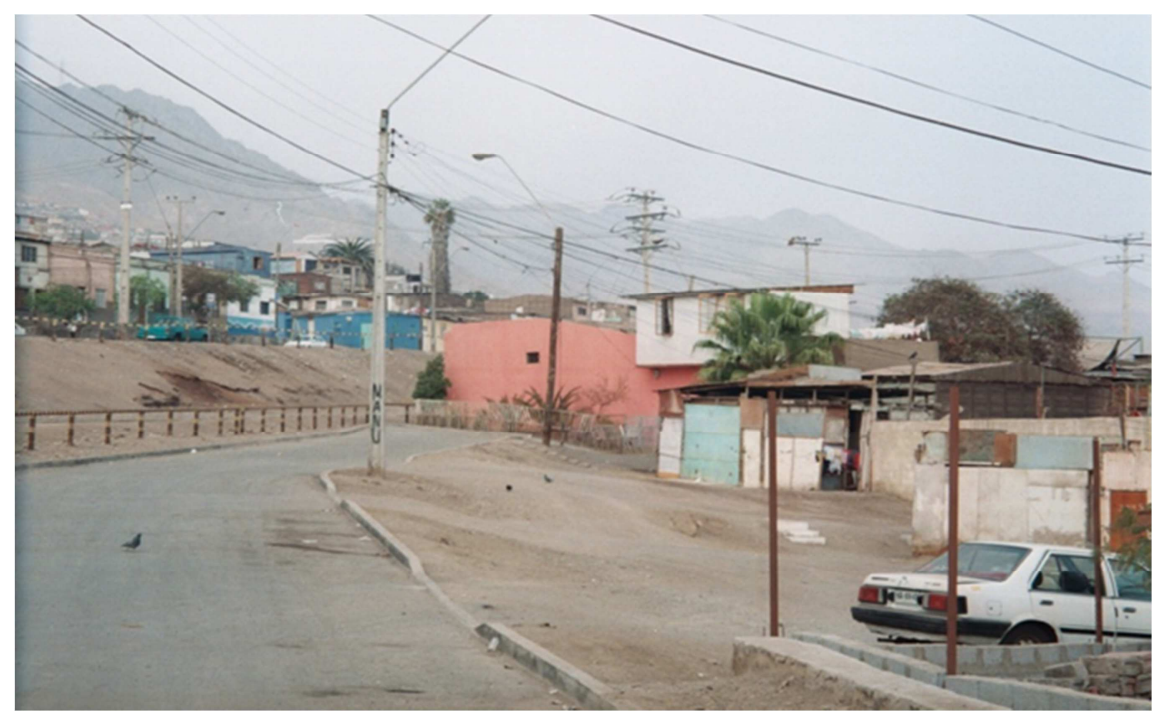

\subsection{Environmental aspects and parameters}

To define vulnerability under an environmental point of view, it is necessary to understand urban systems as biological concepts. Thus, vulnerability depends on the efficiency of the urban metabolism and on its capacity to react to changes. It has to be noticed that an urban system could be efficient but not resilient or vice-versa. Vulnerability is also associated with exposition to risk, that could be a way to assess low efficiencies. Metabolism of cities in terms of efficiency has to consider at least: 
- Energy used in buildings operation, industry and transportation: Energy is critical in urban evaluation, especially in developing countries with energy dependence by third countries. Parameter could be defined as Joules or $\mathrm{kWh}$ per year and distributions (per area, per inhabitant, etc.). Fuel typology has also to be considered, because of the impact on climate change of fossil fuels.

- Materials cycles (including waste and water recycling): Sustainability of cities necessarily has to consider circular flows instead of linear [5]. Presence of recycling plants indicates high standards of quality and resilience. Water usage is especially important in some LatinAmerican regions, like coast deserts of Chile and Peru, where this resource is intensively used by mining industry.

- Economic indicators related to energy intensity: Energy usage could be justified by economic growth, if the inversions are used to develop more sustainable technologies, especially focusing on renewable energy integration. Parameter could be assessed as Joules per millions of dollars or local currency.

- Pollution (air, soil, water, noise, light): Outdoor air quality is expressed by measurement of pollutants concentration provided by monitoring stations. Main contaminants to be considered are: sulphur dioxide $\left(\mathrm{SO}_{2}\right)$, nitrogen oxides $\left(\mathrm{NO}_{2}\right.$ y $\left.\mathrm{NO}_{\mathrm{x}}\right)$, carbon monoxide $(\mathrm{CO})$, heavy metals (lead, cadmium and nickel), ozone, particulate matter $\left(\mathrm{PM}_{10}\right.$ and $\left.\mathrm{PM}_{2,5}\right)$ and polycyclic aromatic hydrocarbons (benzo(a)pyrene). In order to define pollution levels, criteria for outdoor air classification based on WHO (1999) guidelines standards, or equivalent, can be used. Urban noise pollution can be defined by the percentage of inhabitants exposed to A-weighted equivalent sound levels $\left(\mathrm{LA}_{\mathrm{eq}}\right)$ that exceed those considered acceptable. Measurements should be taken over the 24 hour period (day-evening-night equivalent level, $\mathrm{L}_{\mathrm{den}}$ ), over the 12-hour period (day equivalent level, $\mathrm{L}_{\mathrm{d}}$ ) and overnight (night equivalent level, $\mathrm{L}_{\mathrm{n}}$ ). Light pollution refers to excessive luminance of city lights that disturbs sky observation. It has been detected and discussed for many Latin-American cities [6].

\subsection{Social inclusion aspects and parameters}

The relevant aspects referred to the urban decay and social vulnerability issues in Latin-American urban context are: Poverty, Social Decline and Social Cohesion (public participation).

- Poverty: Poverty is a socioeconomic reality that has multiple dimensions which can be reflected in the following characters [7]: A lack of material and cultural resources, a poor access to socio institutional resources and information, and a strong segregation by the rest of civil society. The poverty assessment includes different parameters but in this study we follow the Chilean State Department of Planning (MIDEPLAN) parameter that defines a poverty line based on the family income. The poverty is a relative parameter that must be compared with the poverty average of the city.

- Social Decline: This is one of the most relevant issues to considerer in the definition of Urban Vulnerability, mainly because his modeling capability. The Social Decline of a city can be 
defined by the Social Decline Index (SDI), which is constructed taking into account parameters like extreme poverty, lack of employment, and lack of school attendance.

- Social cohesion and public participation: These are relevant arguments because one of the issues that define a poverty situation is a high social segregation, which can be overcome by the public participation of citizens in the definition of plans and political programs that contribute to improve their social condition. As the citizens' participation is strongly encouraged by their social cohesion, then both issues can generate a resilient social frame.

\subsection{Urban planning aspects and parameters}

These aspects could be assessed at different scales: neighborhood, district and city. Main attention has to be focused on:

- Urban networks: Sewerage system, water distribution, electric power supply, street lights, fire protection and telecommunications. Key aspects to consider will be: adequacy to meet demand, state of preservation, legal framework and management structure of the service.

- Density and distribution: These indicators assess the area per inhabitants, or the number of inhabitants per area, and the relative distribution at the city scale.

- Soil value and urban planning: The presence of regulations is important to equilibrate city living. The soil value could be assessed in money per square meter and indicates the presence of minus values in some critical neighborhood or district. The planning instrument responds to exposition and risk of some city areas and tries to regulate the sensitivity to disasters or changes in population, migration, etc.

- Equipment: Green areas, public spaces and services, schools, hospitals, libraries are all fundamental aspects of high quality of life. It is very important to consider the density and distribution of the equipment in order to assess resilience and efficiency.

\section{Conclusions and future development}

All presented aspects have to be parameterized by using a structure considering risk, exposition and resilience values. Vulnerability results to be a function of them (1):

$$
\text { Vulnerability }=\mathrm{f}(\text { risk, exposition, resilience) }
$$

Risk is the presence of dangerous condition within urban systems, exposition refers to the number of people exposed to this risk and resilience suggests the presence of containment elements to avoid dangerous situations. Indicator construction should be done in relative terms, fixing a minimum and maximum value of each parameter and scaling it between 0 and 1 . 
Main expected achievement of this work will be the proposition of a methodology taking into account all parameters obtained from this selection. As stated in the introduction, several authors warn about the difficulty to mix variables of different sort (countable, uncountable, user-dependent, etc.). In this sense one of the principal ideas of this work is to make use of a fuzzy-logic calculation in order to cut down variables that lead to extreme positive or negative results: a good evaluation in terms of low vulnerability has to include average estimation, avoiding excessive weight of some parameters. Finally, this methodology will be applied to the study of cities like Antofagasta, Arica (both are situated in the North of Chile) and Salta (situated in the North of Argentina), conducing to generate recommendations for the improvement of the urban vulnerability in middle-sized cities.

\section{Acknowledgments}

This work was done thanks to the founding of the UCN School of Architecture and is a part of the Laboratories "Architecture and Energy" and "Urban Design" of the first semester 2014.

\section{Conflict of Interest}

The authors declare no conflict of interest.

\section{References and Notes}

1. Un-Habitat. $7^{\text {th }}$ World Urban Forum Report. 2014 Available on line: http://wuf7.unhabitat.org/wuf7-reporting-and-conclusions

2. Hernández, A.; Vázquez, M. (2010) “Clasificación multicriterio: una regla simple para tratar problemas complejos". Sustentabilidad(es) No 2. Volume 1, pp. 192-208

3. Vancheri, A.; Giordano, P.; Caputo, P. Author, A.; Author, B. "A calculation of urban metabolism". In Acebillo, J. (Ed.) A new urban metabolism; i.CUP Publisher: Mendrisio, Switzerland; 2012

4. Kapstein, P. "Vulnerabilidad y Periferia Interior" in Cuadernos de Investigación Urbanística, Instituto Juan de Herrera de Madrid, 2010 available online: http://www2.aq.upm.es/Departamentos/Urbanismo/institucional/numeros-ciur/ciur-71/

5. Vernay, A.; Rajbeer, S. Circular Urban Systems: Tracing Innovation Processes. In Proceedings of the 2nd World Sustain. Forum, 1 - 30 November 2012; Sciforum Electronic Conference Series, Vol. 2, 2012

6. Atacama Manifesto, Noche Zero. 2012. Available on line: http://www.nochezero.org/wpcontent/uploads/NZ_Atacama-Manifesto.pdf

7. Renes, V; Alguacil, J., et al. "Las condiciones de vida de la población pobre desde la perspectiva territorial. Pobreza y territorio". Equipo de Investigación Sociológica (EDIS), Fundación Foessa y Cáritas, Madrid, 2000.

(C) 2014 by the authors; licensee MDPI, Basel, Switzerland. This article is an open access article distributed under the terms and conditions of the Creative Commons Attribution license. 